\title{
Education For Sustainable Development
}

\author{
Engjellushe Zenelaj ${ }^{1}$ (Doctoral Student)
}

\begin{abstract}
:
The practical definition of sustainable development remains "balance between the social, economic and natural resources". To build a system for sustainable development in progress is very difficult; it should be noted that to talk about the three elements at the same time. Finding balance, adds more difficult, because, "the preservation of the ecosystem", includes in itself, human capital, making peoples an integral part of the ecosystem that we are trying to save. Mostly, sustainable development requires major and radical changes, in particular to human behaviors and habits, connected to nature and the economy. The aim of this article is to identify the role of education in sustainable development. The development of education in the context of sustainable development, promotes the correct answer of science, but a way of engaging with different perspectives on the world we live in, and share together every moment of our lives.
\end{abstract}

Key words: education, sustainable development, education for sustainable development.

\section{Introduction}

Problems posed in front of science and government, how come and grow. Society, more and more, leads us to many questions. Every day confronted with new facts, which are often at stake our future. The world as the coming of "reduced" because we always know more, every corner, but again problems and complexes added.

In addition to the desire, above all, comes the duty to know and to find out as much which obliges us to work and to engage seriously, to solve the problems. Everyone will play his role and his function on the path of common purpose. This bone reason why the development of education, is an educational response that relates to all the changes that focus on activating global society.

Education is seen as a way to manage this entire global crisis; since the only way is knowledge. Only well mannered people, have the power of speech and opinion to make everyone accountable, and to orient them on the path of sustainable development.

${ }^{1}$ Lecturer at Ismail Qemali University of Vlore, Albania 
Education promotes sustainable development, using specific methods to change the world. Finally, Global Learning for Sustainable Development (GLSD) is currently emerging from the increasing international concern with issues of Sustainable Development and the demand for both Global Learning as well as education for sustainable development. (Anderberg, E., B. Nordén and B. Hansson, 2008).

\section{Literature review}

Education for sustainable development is a vision of education that seeks to balance human and economic well-being with cultural traditions and respect for the Earth's natural resources. It emphasizes aspects of learning that enhance the transition towards sustainability including future education; citizenship education; education for a culture of peace; gender equality and respect for human rights; health education; population education; education for protecting and managing natural resources; and education for sustainable consumption. (Arjen E. J. Wals Geke Kieft, , 2003)

Education for sustainable development must continue working with environmental education which brought a new view of human relationships with the world environment - which is no longer conceived as an object, but as a living creature that shares the same destiny with human beings. Environmental knowledge is ethical and political. It isn't only a matter of understanding ecological principles, but also involves a new concept of reality. (Gadotti, 2008)

The relation between education and sustainable development is complex. Generally research shows that basic education is to nation's abilities to develop and achieve sustainable target (Tilbury, 2002)

Some authors imply that unless ESD and generally the discourse on sustainable development (SD) stay open to opinions and debates of educators, it risks becoming indoctrination, a mindless and autocratic repetition of official definitions and limiting standards . (Wals, A.E.J., and B. Jickling. , 2000)

\section{Education and social behavior}

A central aspect of ESD is that learners develop the ability to evaluate global and inter-generational issues and formulate strategies for solving the problems that arise from these issues ( (Almlöv, M. and E. Moberg , 2008:)). If community is not well educated (if hasn't information about the consequences of some action) how could we pretend that they will be active citizens? If the head 
of municipality and his staff has no knowledge in sustainable development, how can we pretend to aspect a for a sustainable community future?

A Confucius Chinese philosopher \& reformer (551 BC - 479 BC), had said "I hear and I forget. I see and I remember. I do and I understand." Logically you do what you think is right, and to decide what is right you need knowledge that the main part of them you have take from school, and another part come from family.

When we talk about "changing behaviors and habits" it has to do directly with the manner and style of life that we do. Change is a difficult process, because it need time to realize. Education is fundamental for changing in local and global scale. Best way to bring about change in the community or society is education. When talking about education, mean education from primary school curricula until they postgraduate. Education is first step of Sustainable development.

Own theory of sustainable development, is not yet consolidated, but still this stage where it is, remains the foundation for all development plans, and future goals. Therefore, the vision of the future is not seen without sustainable development theory that is injected in every direction. People usually do not to prefer to change behaviors of life style. They want their own model to construct and to live their life. Actually almost no one is prepared to be Sustainable. That's because being "Sustainable" requires sacrifices in our accommodated life.

While the theory of sustainable development, is the planet's perspective, on the other hand we have the expression that the "youth are the future". This means that children are prospects. To work for their education to bring change, doubtless can expecting positive results. They are in time to change many of the behaviors that today many of us see as unacceptable. No one can change what encounters happened in the past, but we can address the issues of the present, and attempt to make humanity more sustainable in the future. Education is a very important step in enhancing a generation of people to understand the importance of sustainability.

Education starts with you. Education is pretty fine when combined with personal effort. Everyone after got knowledge is able to know and to act what is good for him. So if everyone knows it, and action, we will be all at the same road, and with the same goals, and with the same level of responsibility. When we say to use education it means not just to teach the concepts but to teach the skills to change ourselves and our habits. Education is the first step in understanding what about sustainability is, and every person that learns about sustainability may learn which are their own impact on their environment, whether positive or negative they are. Education is not alone. After education come implementations. And they both are really closed. 


\section{Education and natural resources}

Environmental protection in Sustainable development discourse is seen as an afterthought to all other pressing human issues such as equality, fair distribution of natural resources (sic!), and human rights, the key concern is that the discourse on SD maintains an instrumental and anthropocentric worldview ( (Kopnina, H. and Keune,H., 2010)).

Education makes clear the differences between standards and quality of life. Sustainable curricula education has started to spread information for quality of life, and especially in the issue of consumerism. Agriculture revolution, and the rapid development in technologies, has created the idea that as much we consume as much better we live. Our society is doubly a consumerism society. In fact the quality of life is really closed with environmental. The clean and fresh air, clean water, bio productions, that are fundamentals elements that we live in this planet, has no connection with the quantity of our day's consumerism. The definition of consumerism is "Consumerism is a social and economic order that encourages the purchase of goods and services in ever-greater amounts. The passing of time, unfortunately, Consumerism is engrained in our culture. There has to be a way to link this with sustainable outcomes which is education. The theory of sustainable development has start from environmental issues, not only to protect environment, natural resources but also to take care for our healthy. Many diseases today are consequences of dirty and damage environmental, unsafely food, water pollution, air pollution.

Human kind can't survive without oxygen, water, land etc. All those elements are part of our environmental. Another strong connection that comes from environmental education is conserving natural resources because we are not only for today here. We must think for tomorrow's generations.

\section{Up with education - up with legislation}

We live in a democratic system, and even other countries that haven't democracy are trying to construct it. Democracy is based on laws. Law is a system of rules and social norms that people have to follow, in a society or country. Laws are implemented by institutions, society and the relevant legal authorities. Law is the formal act, issued by the legislative body of the state, and contains the set of norms that regulate a certain area of life in society. As such law is part of the entire legal system of constitutional. Each law comes as a necessity to regulate the functions of a society. A society tends not to enforce the laws, if it is not aware of the importance of the law. However strong to be law enforcement, against the sovereign, always wins the battle in front of the state. To bring change in the life of the community, deprived of some behaviors, and 
imposing new, and to carry out that peacefully, so that expect positive results, must first community awareness, which comes as a product of education.

\section{Conclusions}

The link between education and sustainable development is strong. The theory of the future for sustainable development, may not receive or find the application development and widespread support, if people are not educated and do not receive adequate information. Implementation of strategies for sustainable development is a result of the development of educational curricula. More and more, today there are efforts to integrate sustainable development theory in education, not only theoretical concepts but also in practical applications. Sustainable development, search from the human society, in the entire world to change some our models living. Actually this is the most difficult point. And this is the reason why the vision of sustainable development must be constructed over the way of education.

To change means that you have understand your responsibility, to be responsible you must have knowledge, and to pretended that you have knowledge you must be educated. If you want to make changes start with children and youth people. Children and youth people are pupils or students, which the main part of the day spends in school, with professors, teachers, making little projects etc. There is the first place when everyone can take good theoretical knowledge and after that will understand the responsibility for every step in this planed. After that university education in sustainable development is very important.

We need to be able to translate information into knowledge, deal with complexity and uncertainties, we need to work effectively with others in very challenging environments at work and in our private life and we need to be good communicators in and between different cultural settings both at home and abroad.

Development and sustainable development is connected with education. We live at the same planet, and planet is like a big home which means that we live at the same home. So we divide problems. We are like a family, and as a big family we must contact with each other, meet, discuss, analyses and then find a common solution. All this is called "Communication" that also is part of education. And many times is needed to remember that environmental issues are not so easy to understand and to give solution. Environmental problems in America are risk for Albania, and environmental problems in Albania are risk for China etc; it goes on so in the entire world. First of all we must arrived some standards, and then pretend for quality. Education for sustainable development is one of the standards that all the country of the word must have it. After this youth people and younger generates start change the manners of live. 


\section{Recommendations}

- The theory of sustainable development should be integrated, more educational curricula at all educational levels.

- It should be treated not simply as a theoretical and conceptual analysis but as practical training.

- Integrate the principles of sustainability cannot be a special subject, but it must be integrated in all the sciences, such as biology, geography, sociology, etc.

- Interaction labor methodologies are assets that guarantee success.

- The identification of educational programs for sustainable education curricula in all states, in this way all will join this, regardless, the level of GDP, ethnic, social affiliation, national borders, geographic or physical barriers etc.

- $\quad$ More Funding for Education programs for sustainable development.

\section{References}

Almlöv, M. and E. Moberg - (2008:). Students in Possession of the Issues of Tomorrow. An Innovative Student-led Course Project . Journal of Education for Sustainable Development. , Vol. 2(2):173-179.

Anderberg, E., B. Nordén and B. Hansson. (2008). Global Learning for Sustainable Development in higher education: recent trends and a critique. International Journal of Sustainability in Higher Education, , 10(4):368378.

Arjen E. J. Wals Geke Kieft, . (2003). Education for sustainable development. 2010: SIDA .

Gadotti, M. (2008). What We Need to Learn to Save the Planet. . International Journal of Education for Sustainable Development. , 2(1):21-30.

Kopnina, H. and Keune,H. (2010). In Health and environmental: Social sciences perspectives. New Yourk: Nova Sciences.

Tilbury, D. (2002). Education for sustainability responding to global challenges,. IUCN .

Wals, A.E.J., and B. Jickling. . (2000). Process-based environmental education seeking standards without standardizing. In Critical environmental and health education: Research issues and challenges. 